\title{
Diagnóstico laboratorial dos protozoários entéricos oportunistas em Goiânia, GO
}

\author{
Laboratonial diagnosis of intestinal protozoan \\ opportunistic infections in Goiânia, GO
}

\author{
Ricardo Souza Manzi e Marco Tulio A. García-Zapata
}

\begin{abstract}
Resumo A criptosporidiose, isosporíase, ciclosporíase e as microsporidioses tornaram-se comuns em pacientes imunocomprometidos. O diagnóstico destas doenças é importante, pois produzem quadro clínico semelhante, mas possuem manejo terapêutico e prognóstico diferente. Visando avaliar a situação do diagnóstico destes parasitas, foram mapeados os laboratórios da rede do SUS e as unidades de saúde no município de Goiânia, GO.
\end{abstract}

Palavras-chaves: Parasitas oportunistas. Diagnóstico laboratorial. AIDS.

Abstract Criptosporidiosis, isosporiasis, cyclosporiasis and microsporídiosis have become common in immunocompromised patients. The diagnosis of these diseases is important, because although they produce similar clinical pictures, they have a different therapeutic approach and prognostic. Seeking to evaluate the situation of the diagnosis of these parasites, the laboratories of the SUS network and health centers of the district of Goiânia-GO were mapped.

Key-words: Opportunistic parasites. Laboratory diagnosis. AIDS.

É sabidamente conhecido, que indivíduos imunosuprimidos estão sujeitos a uma série de complicações infecciosas causadas por agentes oportunistas. E com o surgimento da pandemia da sindrome da imunodeficiência adquirida (AIDS/SIDA) causada pelo vírus da imunodeficiência humana (HIV), observamos notadamente o aparecimento de algumas doenças denominadas emergentes, cujos agentes etiológicos envolvidos só tinham importância, a maioria deles, na medicina-veterinária. Entre estas entidades emergentes, encontramos os protozoários entéricos oportunistas, em especial os coccídios (Filo: Apicomplexa) e os microsporídios (Filo: Microsporidia), relatados como responsáveis por inúmeros casos patológicos, apresentando infecções refratárias ou incuráveis, com significativas causas de morte. Os coccídeos intestinais de maior importância que infectam o trato intestinal humano, são: Isospora belli, Cryptosporidium parvum, e o mais recente agente infeccioso humano, a Cyclospora cayetanensis ${ }^{4}$. Em relação aos microsporídios ${ }^{5}$, apesar da existência de mais de 100 gêneros e cerca de 1.000 espécies pertencentes a este filo, somente - Enterocytozoon bieneusi e Septata intestinalis (atualmente: Encephalitozoon intestinalis), têm sido identificados infectando enterócitos humanos e macrófagos e considerados como agentes mais comuns de enterocolite, existindo relatos de que são responsáveis, entre outras condições clínicas, por $10 \%$ a $30 \%$ de diarréias em pacientes com AIDS/SIDA. A maioria destes parasitas, embora estando em evidência por causa da AIDS/SIDA, e até mesmo acometendo indivíduos imunocopetentes, não é identificada em nosso meio, pelo fato dos médicos desconhecerem a sua importância ou pela falta

Instituto de Patologia Tropical e Saúde Pública da Universidade Federal de Goiás.

Endereço para correspondência: Caixa Postal 12911 - Setor Leste Vila Nova, 74643-970 Goiânia, GO

zapata@iptsp.ufg.br

Recebido para publicação em 6/10/99. 
de um laboratório devidamente preparado para o estudo e caracterização dos agentes etiológicos envolvidos, apesar do conhecimento da existência de técnicas modernas, eficientes e viáveis de coloração coprológica com microscópia óptica ${ }^{6}$. Com essa finalidade, visando avaliar, preliminarmente, a situação do diagnóstico laboratorial destes parasitas na região é que foi estruturado este estudo. Para tal, foram mapeados as unidades de saúde e os seus laboratórios municipais, estaduais e conveniados ao Sistema Único de Saúde (SUS) do estado de Goiás, localizados no município de Goiânia, assim como as técnicas utilizadas por eles para o diagnóstico parasitológico, com especial ênfase aos coccídios intestinais e microsporídios. Inicialmente, realizou-se um levantamento das unidades de saúde, com posterior captação das informações mediante uma ficha padrão. Foram identificadas no total 62 unidades, distribuídas geograficamente em nove Distritos Sanitários: 6 Hospitais e 0 Laboratório Central de Saúde pública (LACEN) de responsabilidade da esfera estadual, 2 hospitais filantrópicos, 1 hospital federal $(\mathrm{HC})$, 2 laboratórios universitários (IPTSP e LRR/FF), 9 Centros de Atendimento Integrado à Saúde (CAIS), 4 Centros Integrados de Assistência Médica à Saúde (CIAMS), 1 Centro de Zoonose, 1 Centro Especializado em DST/AIDS e 35 Centros de Saúde (CS), subordinados à Secretaria Municipal de Saúde do Município de Goiânia/SMS, GO. Desses, apenas do CIAMS do Jardim América não se obteve informações. Na avaliação, constatouse que somente em 23 (37\%) dessas unidades é realizado algum tipo de estudo parasitológico de rotina, denominado como exame parasitológico de fezes (EPF). O método de sedimentação espontânea ${ }^{3}$ serviu como método padrão para o exame de rotina, sendo que a técnica de centrifugação e flutuação de Faust, o método de Rugai e a técnica de Baermann-Moraes, foram consideradas complementares, nos casos considerados necessários. Somente em 4 (6,4\%) das unidades é utilizado alguma forma para preservar o material (formol $10 \%$, MIF e a frio). O método de concentração formol-éter modificado (Ridley) foi feito apenas no LACEN e IPTSP/UFG. O diagnóstico específico de oocistos de Cryptosporidium sp. e I. belli, foi relatado em 3 $(4,8 \%)$ das unidades: LACEN, Hospital das Clínicas/UFG e IPTSP/UFG. Destes, o primeiro utilizou a coloração Ziehl Nielsen modificada, coloração fucsina-carbólica (método Kinyoun) e a técnica de esporulação pelo bicromato de potássio; enquanto que o segundo contava apenas com a coloração Ziehl Nielsen modificada com verde malaquita como contraste. O IPTSP é o único que dispõe de ocular micrométrica, instrumento indispensável para o diagnóstico conclusivo para diferenciar o $C$. parvum (4 a $6 \mu$ ) da $C$. cayetanensis ( 8 a $10 \mu$ ), em virtude das semelhanças em suas características tintoriais e morfológicas ${ }^{1}$, e dispõe de um arsenal completo para o estudo dos parasitas oportunistas. Os dados expostos acima, mostram a carência de métodos para o diagnóstico destes agentes entéricos e confirmam a necessidade de se implantar técnicas e métodos racionais na rede do SUS. A identificação desses agentes é importante, pois eles podem produzir quadro clínico semelhante mas de manejo terapêutico e prognóstico diferente ${ }^{2}$.

\section{REFERÊNCIAS BIBLIOGRÁFICAS}

1. González-Ruiz A, Bendall R. Size matters: the use of the ocular micrometer in diagnostic parasitology. Parasitology Today 11:83-85, 1995.

2. Hamour AA, Mandal BK. Coccidian Parasites in patients with AIDS: Cryptosporidiosis, Microsporídiosis, Isosporiasis and Cyclosporiasis. Balliére's Clinical Infectious Diseases 3:137-153, 1996.

3. Lutz A. O schistosomum mansoni e a schistosomatose, segundo observações feitas no Brazil. Memórias do Instituto Oswaldo Cruz 11:124-155, 1949.

4. Ortega YR, Sterling CR, Gilman RH, Cama VA, Diaz F. Cyclospora species - a new protozoan pathogen of humans. New England Journal of Medicine 328:13081312, 1993.

5. Simon LC, Willians J, McGowan I. Intestinal microsporídiosis. Seminars in Gastrointestinal Disease 8:45-55, 1997.

6. Weber R, Bryan RT, Owen RL, Wilcox CM, Gorelkin L, Visvesvara GS. Improved light-microscopial detection of microsporidia spores in stool and duodenal aspirates. The Enteric Opportunistic Infections Working Group. The New England Journal Medicine 326:161-166, 1992. 